\title{
Construction of a novel oncolytic adenoviral vector and its biological characteristics
}

\author{
MINGZHI ZHANG ${ }^{1,3}$, XUDONG ZHANG $^{1}$, ZHIQIANG HAN ${ }^{2}$, \\ XINFENG CHEN ${ }^{1}$, LI YANG $^{3}$, YUQIAO SHENG ${ }^{3}$ and JIANGUO WEN ${ }^{3}$ \\ ${ }^{1}$ Oncology Department of the First Affiliated Hospital of Zhengzhou University; ${ }^{2}$ Medical College of Zhengzhou University; \\ ${ }^{3}$ Institute of Clinical Medicine of the First Affiliated Hospital of Zhengzhou University, Zhengzhou 450000, P.R. China
}

Received August 15, 2012; Accepted October 12, 2012

DOI: $10.3892 /$ or.2012.2140

\begin{abstract}
In this study, we aimed to construct an effective and safe oncolytic adenoviral vector for cancer treatment with gene therapy. First, the promoter of the catalytic subunit of human telomerase (hTERTp), adenovirus early region la gene (E1A) and thymidine kinase gene of human herpes virus type 1 (HSV-1-TK) were amplified by using PCR from genomic DNA of 293A cells and wild-type HSV-1 (wHSV-1). These speciallyprepared elements were inserted into an adenoviral shuttle vector in the opposite and the same directions of left inverted terminal repeat (L-ITR), respectively, to construct pENTR-E1A-IRESTK-hTERTp (pEITH) and pENTR-hTERTp-E1A-IRES-TK (pHEIT). LR reaction between adenoviral shuttle vectors (pEITH and pHEIT) and the backbone vector DEST was carried out to establish adenoviral expression vectors pAd-E1A-IRESTK-hTERTp (pAd-EITH) and pAd-hTERTp-E1A-IRES-TK (pAd-HEIT). Recombinant adenovirus Ad-EITH and Ad-HEIT were produced by transfecting 293A cells and purified for the subsequent studies of titer measurement, replication capability with and without acyclovir (ACV) and antitumor ability with and without ganciclovir (GCV) to evaluate the biological characteristics. Adenoviral shuttle vectors pEITH and pHEIT and expression vectors pAd-EITH and pAd-HEIT were successfully constructed, and recombinant adenoviruses Ad-EITH and Ad-HEIT with high titer were produced. The results of replication and cytotoxicity assays showed that Ad-EITH and Ad-HEIT replicated in the hTERTp (+) human nasopharyngeal carcinoma cell line CNE and expressed the TK gene effectively leading to the death of tumor cells. In addition, there were still some Ad-HEIT particles replicating in the hTERTp (-) human osteosarcoma U-2OS cells and human lung HFL-1 fibroblasts compared to Ad-EITH which was hardly able to replicate
\end{abstract}

Correspondence to: Professor Mingzhi Zhang, Department of Oncology, the First Affiliated Hospital, Zhengzhou University, 1 Jianshe Road, Henan, Zhengzhou 450000, P.R. China

E-mail: mingzhi_zhang1@163.com

Key words: oncolytic adnovirus, hTERT promoter, thymidine kinase gene, tumor cells, acyclovir in U-2OS and HFL-1 cells. In addition, we also observed an interesting phenomenon, that the replication of Ad-EITH could be inhibited by antiviral drug ACV on account of the expression of HSV-1-TK gene making Ad-EITH sensitive to ACV. In conclusion, a novel oncolytic adenoviral vector Ad-EITH was produced which can be used for cancer-specific and efficient viral replication, and its safety is potentially improved as replication can be inhibited by ACV in vitro.

\section{Introduction}

Cancer is a malignant disease which threaten human life severely, and the traditional treatments include surgery, chemotherapy and radiotherapy by which cancer can rarely be cured. Gene therapy is a newly emerging therapeutic tool to treat cancer with viral vectors and nonviral vectors, the viral vectors such as adenovirus, retrovirus and herpesvirus have been used in preclinical and clinical trials, and adenoviral vectors have even been used in clinical treatments for cancer patients $(1,2)$.

Adenoviral vectors are usually reconstructed to replication defective vectors and oncolytic adenovirus (3). Replication defective vectors could not spread overall into tumor tissue because of the low genetic expression level. Oncolytic adenovirus, also referred to as conditionally replicating adenovirus (CRAD), can selectively replicate in tumor cells and cause cell lysis. The released viral particles subsequently infect neighboring tumor cells and lead to tumor lysis and regression, therefore construction of oncolytic adenovirus was developed $(4,5)$. On the one hand, tumor-specific promoters were considerably used to construct CRAD by driving replication-essential gene to control viral replication in selective tumor cells. For example, CRAB-CG7870 constructed by using PSA promoter to regulate E1A gene was able to infect and kill prostatic carcinoma effectively in a clinic trial (6). Other studies have demonstrated that the promoter of catalytic subunit of human telomerase (hTERTp) could be a good tumor-specific promoter (7) and telomerase-selective oncolytic adenoviral agents could significantly suppress cancer growth $(8,9)$. Exogenetic genes were utilized to enhance the anticancer effectiveness of oncolytic adenovirus. Suicide gene therapy by using the herpes simplex virus thymidine kinase/ ganciclovir (HSV-TK/GCV) system is a well-characterized 
tool used in cancer gene therapy (10-12). TK gene was able to transform ganciclovir (GCV) into GCV-TP which inhibit DNA synthesis and induce host cells death, but suicide gene such as TK gene also induced normal cells death, so the problem of regulation of suicide gene expression needs to be resolved. Zhang et al constructed expression vector by using TK gene regulated by MDR1 promoter and improved the antitumor specificity (13). Combination of tumor-specific promoter and exogenetic antitumor gene has been thought to be an ideal strategy for gene therapy, for example Zhang et al (14) constructed adenoviral vector by using TK gene and E1A gene regulated by the promoter of catalytic subunit of human telomerase gene (hTERTp), and demonstrated its potential antitumor value. Unfortunately, further research found that a small number of viral particles could infect and replicate in normal cells but let some malignant cells slip away and enabled cancer survival $(15,16)$, so innovative construction of oncolytic adenovirus should be performed for better effectiveness and specificity.

Left and right inverted terminal repeat (17-19) in adenoviral genome as cis-acting elements are essential for viral replication, and L-ITR sequence possesses promoter and enhancer activity that could influence the expression of genes downstream, and it was found that L-ITR contained the sole promoter for E1A (20). In the present study, adenoviral shuttle vector pENTR-hTERTp-E1A-IRES-TK (pHEIT) and pENTR-E1A-IRES-TK-hTERTp (pEITH) carrying hTERTp, TK and E1A elements were first cloned, and then LR reaction between adenoviral shuttle vectors pHEIT and pEITH and backbone vector DEST was carried out to establish adenoviral expression vector pAd-E1A-IRES-TK-hTERTp (pAd-EITH) and pAd-hTERTp-E1A-IRES-TK (pAd-HEIT). E1A-IRESTK-hTERTp was inserted in pAd-EITH in reverse direction of L-ITR and hTERTp to be 'far away' from the promoter and enhancer sequence in L-ITR, which enabled a better specificity for hTERT promoter, while E1A-IRES-TK-hTERTp was cloned to the contrary in pAd-HEIT as a control.

Recombinant adenovirus Ad-E1A-IRES-TK-hTERTp (Ad-EITH) and Ad-hTERTp-E1A-IRES-TK (Ad-HEIT) were produced by using 293A cells and purified for the subsequent test of titer measurement, replication capability with and without acyclovir and antitumor ability with and without ganciclovir to study the biological characteristics. As a results, we found that Ad-EITH replicated more selectively in hTERTp (+) cells than Ad-HEIT because tumor-specific promoter was used to control adenovirus replication-essential gene E1A with little nonspecific regulation effects by L-ITR. Suicide gene TK co-expressing with E1A not only enhance the specific anticancer effect but also make recombinant adenovirus Ad-EITH sensitive to the antiviral drug acyclovir which means that we could utilize this characteristic to eliminate the remaining viral vectors in the future clinical use, therefore we supposed that Ad-EITH could be a potential oncolytic adenovirus with better effectiveness and safety for cancer treatment.

\section{Material and methods}

Cell lines. Human embryonic kidney 293A cell line was purchased from Invitrogen, human nasopharyngeal carcinoma
Table I. Amplification and identification primers.

\begin{tabular}{|c|c|c|}
\hline & Primers & $\begin{array}{l}\text { Size } \\
\text { (bp) }\end{array}$ \\
\hline \multirow[t]{2}{*}{ E1a amplification primer } & atgagacatattatctgcca & \\
\hline & tatggcetggggegtttacag & 986 \\
\hline \multirow[t]{2}{*}{ hTERTp amplification primer } & cgattcgacctctctccgetggggc & \\
\hline & cagggcttcccacgtgcgcagcag & 406 \\
\hline \multirow[t]{2}{*}{ TK amplification primer } & aagaggtgcgggagtttc & \\
\hline & ctatgacggcaataaaaa & 1227 \\
\hline \multirow[t]{2}{*}{ E1a identification primer } & tgatcgatcttacctgccac & \\
\hline & ccaaacccaccactctatc & 243 \\
\hline \multirow[t]{2}{*}{ hTERTp identification primer } & tggattcgcgggcacagac & \\
\hline & gcggaaaggaaggggaggg & 191 \\
\hline \multirow[t]{2}{*}{ TK identification primer } & cgtacccgagccgatgact & \\
\hline & tgagggccacgaacgccag & 341 \\
\hline
\end{tabular}

cell line CNE, human osteosarcoma cell line U-2OS and human lung fibroblasts HFL-1 were obtained from the Institute of Cell Biology at the Chinese Academy of Sciences, Shanghai, China. 293A cells were grown in Dulbecco's modified Eagle's medium supplemented with $10 \%$ fetal bovine serum, $0.1 \mathrm{mM}$ nonessential amino acid and $2 \mathrm{mM}$ glutamine. U-2OS cells were grown in McCoy's 5a medium supplemented with $10 \%$ fetal bovine serum and $1.5 \mathrm{mM}$ glutamine. HFL-1 cells were grown in MEM $\alpha$ medium supplemented with $10 \%$ fetal bovine serum. All the cells were cultured at $37^{\circ} \mathrm{C}$ in a humidified incubator with $5 \% \mathrm{CO}_{2}$.

Plasmids, virus and bacterial strains. All plasmids (pMD18-T, pGM-T, pENTR-MCS, DEST and pIRES) used in this experiment were gifts by Professor Han Zhiqiang of Zhengzhou University. Wild-type human herpes virus type 1 and competent E. coli DH5 $\alpha$, TOP10 were gifts by Professor Han Zhiqiang of Zhengzhou University.

Construction of cloning vectors pMD18-T-hTERTp, pGM-TTK and $p G M-T-E 1 A$. The 293A cells and wHSV-1 genome were extracted and PCR primer were designed (Table I) and fragments of hTERTp, E1A and HSV-1-TK were amplified by using PCR from 293A cells and wHSV-1 genome, respectively, and cloned into T-vectors by using T-A cloning technology to construct pMD18-T-hTERTp, pGM-T-TK and pGM-T-E1A. Three cloning vectors were identified by sequencing.

Construction of adenovirus shuttle vectors $p E I T H$ and $p H E I T$. Elements of hTERTp, TK, E1A and IRES were cloned into pENTR-MCS by using restriction enzyme and recombinant DNA technology to construct adnovirus shuttle vectors pEITH and pHEIT. All the clones and subclones constructed in this process were identified by restriction enzyme analysis. The strategy of construction is shown in Fig. 1.

Construction of adnovirus expression vectors pAd-EITH and $p A d-H E I T$. LR reaction between adenoviral shuttle vector 


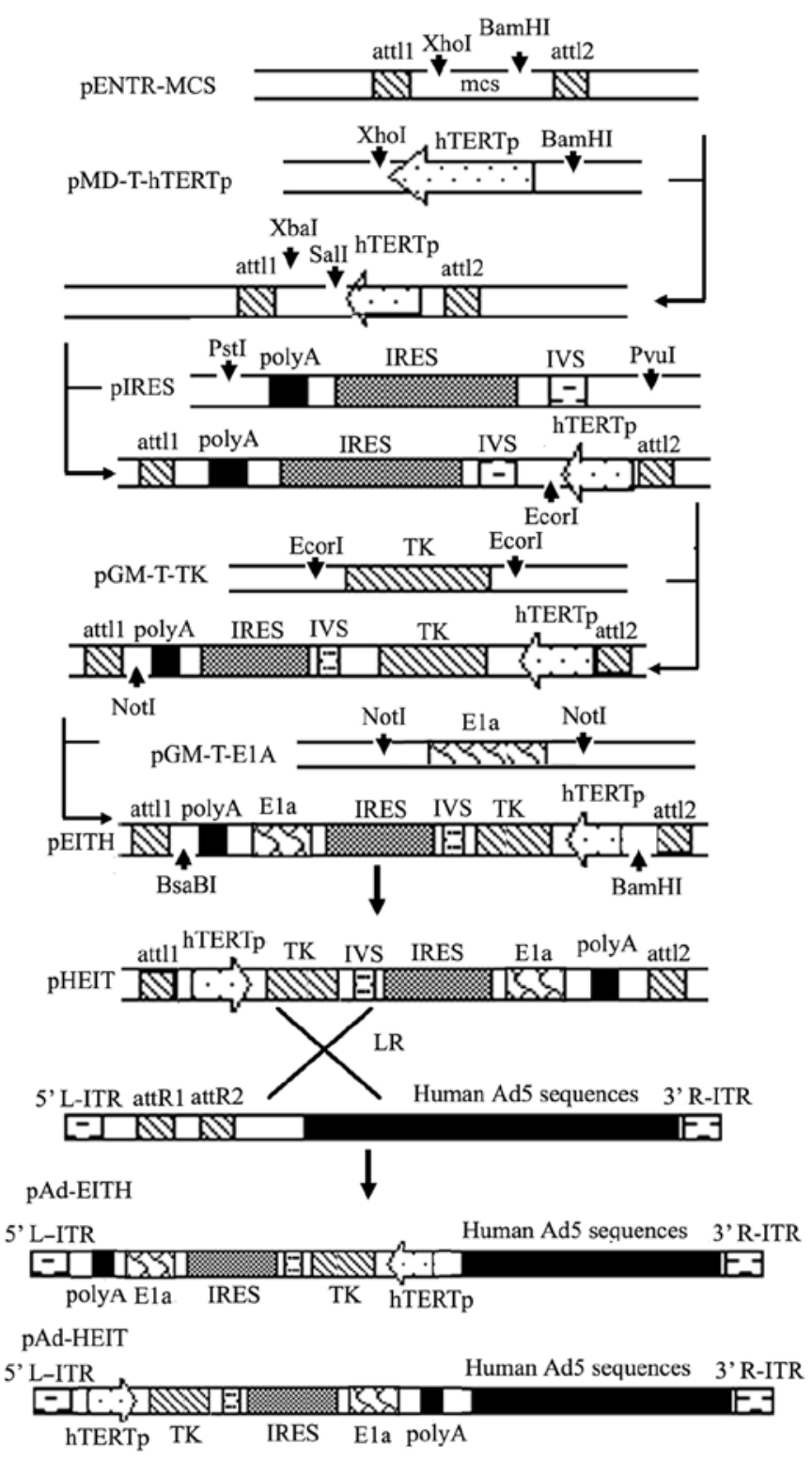

Figure 1. Schematic strategy of adenovirus expression vectors. Elements of hTERTp, TK, E1A and IRES were cloned into pENTR-MCS by using restriction enzyme and recombinant DNA technology to construct adnovirus shuttle vectors pEITH and pHEIT.

(pEITH and pHEIT) and backbone vector DEST was carried out to establish adenoviral expression vectors pAd-EITH and pAd-HEIT in accordance with the manufacturer's instructions: $0.5 \mu 1 \mathrm{pEITH}(\mathrm{pHEIT})+0.8 \mu 1$ DEST $+6.7 \mu$ Eluent $+2 \mu 1 \mathrm{LR}$ recombinase, $25^{\circ} \mathrm{C}$ overnight. Transformed clones were identified by BamHI restriction enzyme analysis.

Production of recombinant adenovirus Ad-EITH and Ad-HEIT

Packaging. The 293A cells were seeded at a density of $5 \times 10^{5}$ cells per well in 6-well plates and transfected with linearized pAd-EITH and pAd-HEIT by using Liposome 2000, cells and supernatant were harvested until $\sim 80 \%$ cytopathic effect (CPE) was observed (5-7 days post-transfection). Cells were lysed to release intracellular viral particles by three freeze/ thaw cycles. The cell lysate was then centrifuged at $5000 \mathrm{rpm}$ for $15 \mathrm{~min}$ at room temperature to pellet the cell debris. The supernatant was then put through a $0.22-\mu \mathrm{m}$ filter and transferred to cryovials in $1 \mathrm{ml}$ aliquots.

Amplification. Isolated plaques of recombinant adenovirus were picked and expanded by infecting 293A cells. On the day before infection, $3 \times 10^{6}$ cells were prepared per $10-\mathrm{cm}$ plate. On the day of infection, the desired amount of virus was added to the cells $(\mathrm{MOI}=10)$ at $80-90 \%$ confluence. The cells and supernatant were harvested, frozen and thawed three times, the cell lysate was centrifuged and stored at $-80^{\circ} \mathrm{C}$.

Identification. The genome of isolated plaques of recombinant adenovirus Ad-EITH and Ad-HEIT was extracted, the identification primer of hTERTp, TK and E1A was designed (Table I) for PCR amplification.

Concentration and purification. The virus mixture solution was transfered with $1.37,1.32$ and $1.27 \mathrm{~g} / \mathrm{ml} \mathrm{CsCl}$ successively to a tube for SW40 rotor, and the balance tube was prepared. The gradient in an SW40 rotor was centrifuged at $35000 \mathrm{rpm}$, $4^{\circ} \mathrm{C}$ for 18 to $24 \mathrm{~h}$. Virus fraction was collected by puncturing the tube just below the virus band and drawing the virus down into the needle. The virus solution was transfered into PBS dialysis cassette for 1-2 $\mathrm{h}$, changing the buffer to fresh PBS with $10 \%$ glycerol after the first dialysis and dialyzing overnight then quantifying the virus before storing at $-80^{\circ} \mathrm{C}$. The titer was determined according to TCID50 methods based on plaqueforming unit assay $(1,2)$.

Evaluation of characteristics of replication. Replicationdeficient adenovirus DEST was used as negative control to evaluate the replication ability of Ad-EITH and Ad-HEIT in CNE cells (hTERT ${ }^{+}$), U-20S cells (hTERT) and normal human cells HFL-I (hTERT). Cells $\left(1 \times 10^{5}\right)$ were seeded in 6-well plates on the day of infection. Viruses were used to infect cells at MOI=10 for $48 \mathrm{~h}$. Cells and supernatant were then harvested and titrated. The replication ability of viruses was evaluated according to the titer.

Sensitivity of Ad-EITH and Ad-HEIT to ACV on account of HSV-TK gene inserted in viral genome was also evaluated in this study. The 293A cells were infected by Ad-EITH, Ad-HEIT and DEST as control for $1.5 \mathrm{~h}$ and washed by PBS, then cultured in DMEM media with $10 \mu \mathrm{g} / \mathrm{ml} \mathrm{ACV}$ and without serum for $48 \mathrm{~h}$. Cells and supernatant were harvested and titrated. The ACV-sensitivity of viruses was then evaluated according to the titer.

Cytotoxicity assay. Cell counting kit-8 (CCK-8) was used for recombinant adenoviruses Ad-EITH and Ad-HEIT cytotoxicity assay to three kinds of tumor cells. First, $100 \mu \mathrm{l}$ of cell suspension $\left(1 \times 10^{4}\right.$ cells/well $)$ in a 96 -well plate was dispensed, and Ad-EITH, Ad-HEIT and DEST were added into the culture media in the plate (MOI=1), other groups were also added with the three viruses at $10 \mu \mathrm{g} / \mathrm{ml} \mathrm{GCV}$. The plates were incubated for 4 days in humidified incubator then CCK- 8 solution was added to each well for assay. The absorbance at $450 \mathrm{~nm}$ was measured using a microplate reader after incubating the plate for $4 \mathrm{~h}$. Inhibition rates then were measured.

Statistical analysis. Statistical analysis was performed with one-way ANOVA and t-test. Statistical significance was set at $\mathrm{P}<0.05$. 


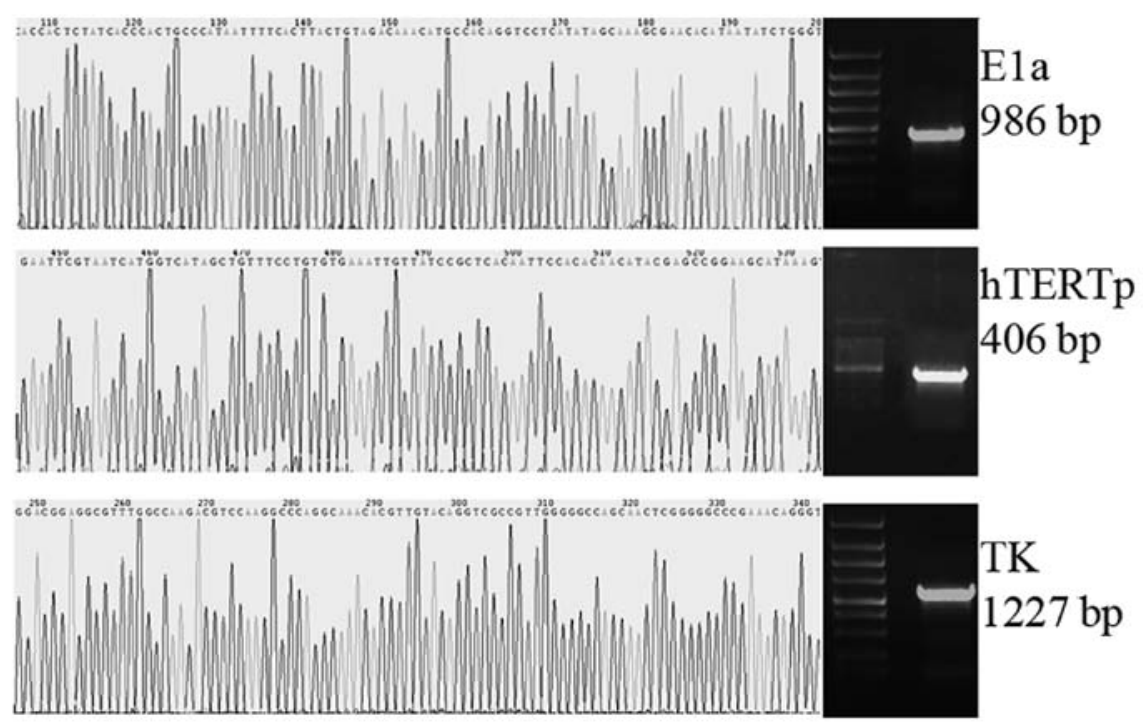

Figure 2. Amplification of E1A, hTERTp, TK and its sequencing. Fragments of hTERTp, E1A and HSV-1-TK were amplified by using PCR from 293A cells and wHSV-1 genome, respectively, and cloned into T-vectors to construct pMD18-T-hTERTp, pGM-T-TK and pGM-T-E1A. Three cloning vectors were identified by sequencing.

A
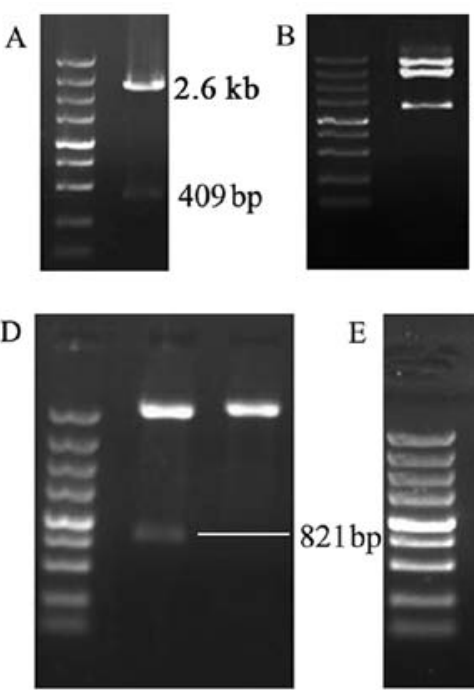

$1.3 \mathrm{~kb}$

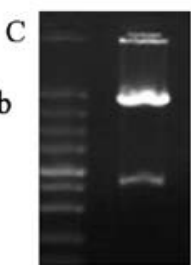

$870 \mathrm{bp}$

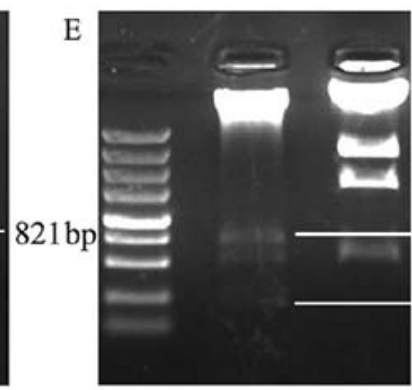

$2.6 \mathrm{~kb}$

$1.5 \mathrm{~kb}$

$822 \mathrm{bp}$

$516 \mathrm{bp}$

$261 \mathrm{bp}$

Figure 3. Identification of pEITH, pHEIT, pAd-EITH and pAd-HEIT. All the clones and subclones in construction of pEITH, pHEIT, pAd-EITH and pAd-HEIT were identified by restriction enzyme analysis.

\section{Results}

Construction of $p M D-T-h T E R T p, p G M-T-T K$ and $p G M-T$ E1A. hTERTp (406 bp), E1A (986 bp) and HSV-1-TK gene (1227 bp) were successfully amplified from the 293A cell genome and wHSV-1 genome respectively, and then pMD-ThTERTp, pGM-T-TK and pGM-T-E1A were constructed by T-A cloning technology and identified by sequencing (Fig. 2).

Construction of pEITH, pHEIT and pAd-EITH, pAd-HEIT. Vector pENTR-hTERTp was cloned by inserting hTERTp into vector pENTR-MCS, recombined vectors were identified by restriction enzyme analysis (Bam $\mathrm{HI}$ and $\mathrm{XhoI})$, correct clone could be cut off to $409 \mathrm{bp}$ and $2.6 \mathrm{~kb}$ fragments (Fig. 3). IRES element was cloned into pENTR-hTERTp to obtain pENTR-
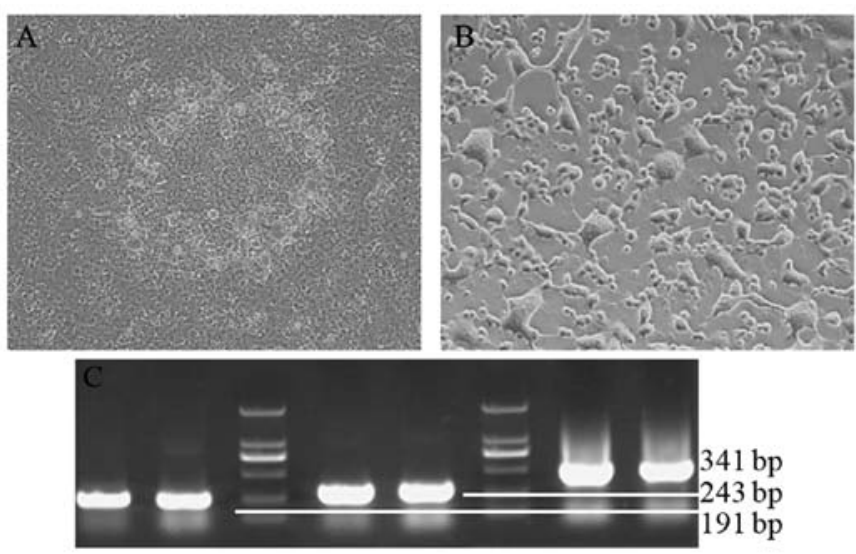

Figure 4. Production of recombinant adenovirus. (A) Isolated plaques of recombinant adenovirus were also picked to obtain the monoclonal virus (B) CPE (cytopathic effect). (C) Extract genome of recombinant adenovirus Ad-EITH and Ad-HEIT, and identified hTERTp, E1A and TK gene by PCR the results show hTERTp, E1A and TK were successfully cloned into the adenoviral genome.

hTERTp-IRES, $1.3 \mathrm{~kb}$ could be cut off from correct clone by BamHI restriction enzyme (Fig. 3). The TK gene was inserted downstream of the hTERTp into pENTR-hTERTp-IRES to establish pENTR-hTERTp-TK-IRES, $X b a \mathrm{I}$ was used in the identification (Fig. 3). pEITH was constructed by inserting E1A gene into pENTR-hTERTp-TK-IRES downstream of IRES and in pEITH hTERTp-TK-IRES-E1A was located downstream of recombination site attL2 with the same direction, hTERTp-TKIRES-E1A was cut off and inserted into pENTR-MCS in the opposite direction compared with pEITH. Vectors pEITH and pHEIT were identified by $S p h$ I (Fig. 3).

LR reaction between adenoviral shuttle vector (pEITH and pHEIT) and backbone vector DEST was carried out to establish adenoviral expression vector pAd-EITH and pAd-HEIT, and BamHI was used in the identification (Fig. 3). 

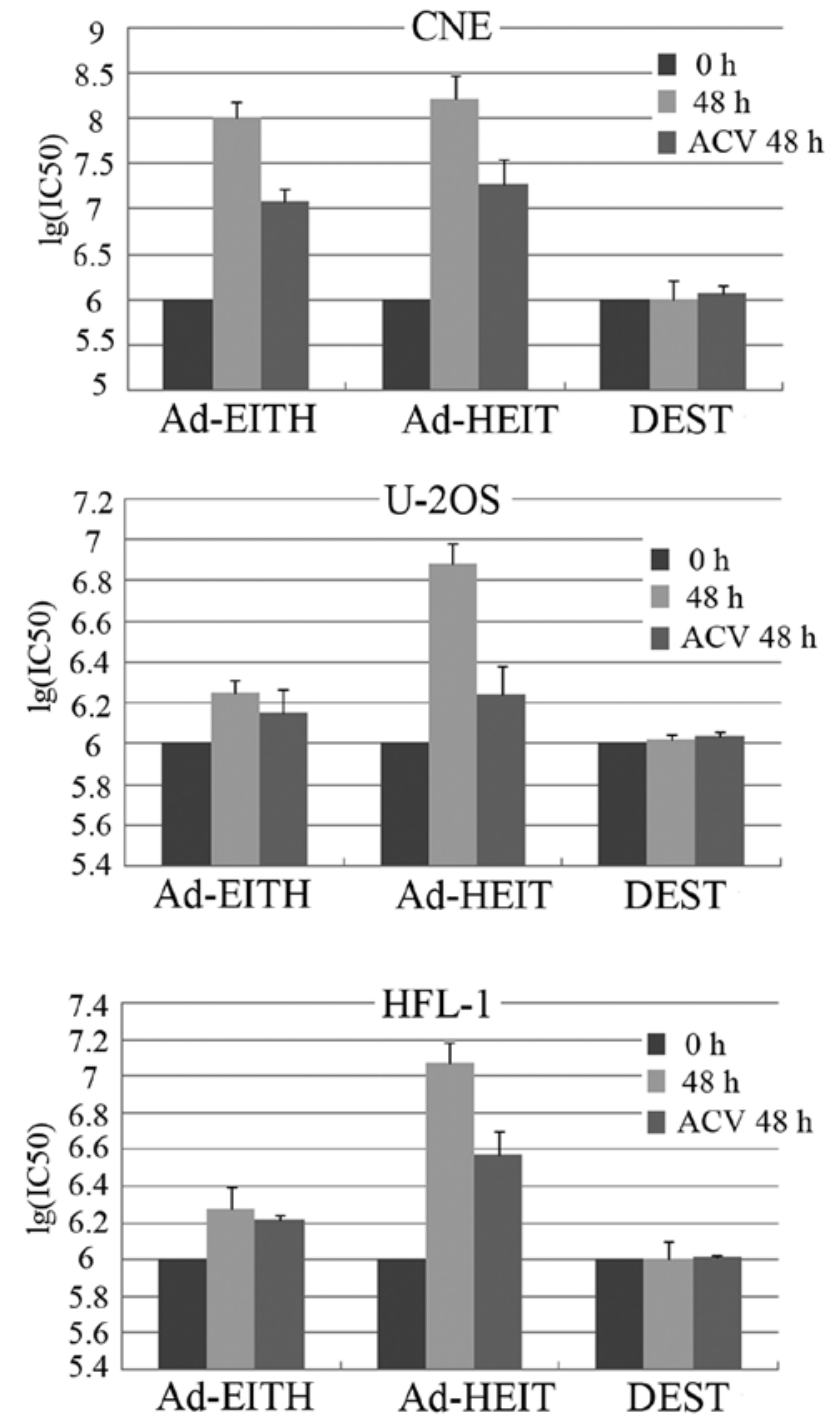

Figure 5. Replication and sensitivity to ACV of recombinant adenovirus. The replication ability of Ad-EITH and Ad-HEIT and their sensitivity to ACV in CNE cells (hTERT), U-2OS cells (hTERT) and normal human cells HFL-1 were evaluated. Error bar: mean \pm SD of five independent experiments.

Preparation of recombinant adenovirus. Adenovirus expression vectors were linearized by $P a c I$ and transfected into 293A cells to package recombinant adenovirus, and the supernatant was harvested until $\sim 80 \% \mathrm{CPE}$ was observed (Fig. 4). Isolated plaques of recombinant adenovirus were also picked to obtain the monoclonal virus (Fig. 4). Amplified crude viruses were concentrated and purified with $>10^{11} \mathrm{PFU} / \mathrm{ml}$. The genome of isolated plaques of recombinant adenovirus Ad-EITH and Ad-HEIT, was extracted and the hTERTp, E1A and TK gene was identified by PCR, the results showed hTERTp, E1A and TK were successfully cloned into the adenoviral genome (Fig. 4).

Replication of recombinant adenoviruses and sensitivity to ACV. The replication ability of Ad-EITH and Ad-HEIT and their sensitivity to ACV in CNE cells (hTERT ${ }^{+}$), U-2OS cells (hTERT) and nomal human cells HFL-1 were evaluated. Results showed that Ad-EITH and Ad-HEIT could both replicate in CNE cells effectively with titer up to $10^{8.01} \mathrm{PFU} / \mathrm{ml}$ and $10^{8.22} \mathrm{PFU} / \mathrm{ml}$ after $48 \mathrm{~h}$ with no significant difference
(P>0.05). while replication ability of Ad-EITH in hTERT (-) U-2OS and human normal HFL-1 cells was weaken obviously and was hardly able to replicate in the cells (titer were up to $10^{6.25} \mathrm{PFU} / \mathrm{ml}$ in U-2OS cells and $10^{6.28}$ in HFL-1 cells). Ad-HEIT replicated in U-2OS and HFL-1 cells at a higher level than Ad-EITH $(\mathrm{P}<0.05)$, and the titer increased to $10^{6.88}$ $\mathrm{PFU} / \mathrm{ml}$ and $10^{7.07} \mathrm{PFU} / \mathrm{ml}$ in U-2OS cells and HFL-1 cells (Fig. 5). In addition, the replication of Ad-EITH and Ad-HEIT was inhibited by ACV. In CNE cells at $10 \mu \mathrm{g} / \mathrm{ml} \mathrm{ACV}$, and the titer of Ad-EITH and Ad-HEIT were up to $10^{7.08} \mathrm{PFU} / \mathrm{ml}$ and $10^{7.27} \mathrm{PFU} / \mathrm{ml}$, both lower than that in CNE cells without ACV $(\mathrm{P}<0.05)$, moreover in U-2OS and HFL-1 cells with $\mathrm{ACV}$, replication of Ad-EITH and Ad-HEIT was also inhibited (Fig. 5) and control virus DEST could not replicate in any of the cells (Fig. 5).

Cytotoxicity assay. Cytotoxicity of recombinant adenoviruses Ad-EITH and Ad-HEIT to tumor cells was evaluated by CCK-8 assay. Morphology observation showed that the three cell types infected by DEST could still grow without obvious morphological changes. While CNE cells infected by Ad-EITH and Ad-HEIT had CPE consisting of cell rounding, disorientation, swelling or shrinking, detachment from the surface and fusion. Compared to Ad-HEIT, Ad-EITH showed less cytotoxicity to U-2OS and HFL-1 cells with slight CPE, most U-2Os and HFL-1 cells infected by Ad-EITH could grow similarly to the DEST group (Fig. 6).

Results of CCK-8 assay showed that Ad-EITH and Ad-HEIT killed CNE cells effectively with 34.7 and $36.4 \%$ inhibition rate, respectively, at MOI=1 ( $P>0.05)$, but Ad-EITH could not inhibit the growth of U-2OS and HFL-1 cells well compared to Ad-HEIT, which still killed 26.4 and $28.6 \%$ U-2OS and HFL-1 cells, that mean Ad-EITH had a better specificity to kill hTERTp (+) tumor cells than Ad-HEIT. Results also showed that GCV enhanced the antitumor effects of Ad-EITH and Ad-HEIT because of the suicide gene TK. The inhibition rates of Ad-EITH and Ad-HEIT were 50.1 and $53.1 \%$ to CNE cells with $10 \mu \mathrm{g} / \mathrm{ml}$ GCV, higher than that without GCV 34.7 and $36.4 \%(\mathrm{P}<0.05)$. However, DEST also had 12.9, 14.5 and 5.5\% inhibition rates to the three cells probably because of some nonspecific effect of virus particles (Fig. 6).

\section{Discussion}

There are many limitations for traditional therapies including chemotherapy, surgery in cancer treatment, so developments of safe and effective biotherapies have been focused on, in recent years. Gene therapy has been used with success and has many advantages. Construction of efficient and safe vectors is the key for gene therapy, and viral vectors are mostly used in gene therapy. Gendicine, an adenoviral p53-based gene therapy was approved by the Chinese food and drug regulators in 2003 for treatment of head and neck cancer. Advexin, a similar gene therapy approach from Introgen, was turned down by the US Food and Drug Administration (FDA) in 2008 (21). However, these replication-defective viral vectors had many problems relating to patient toxicity, immune and inflammatory responses, and gene control and targeting issues, therefore, replication-competent viral vectors (oncolytic virus) were developed (12). It was found that in the absence of repli- 

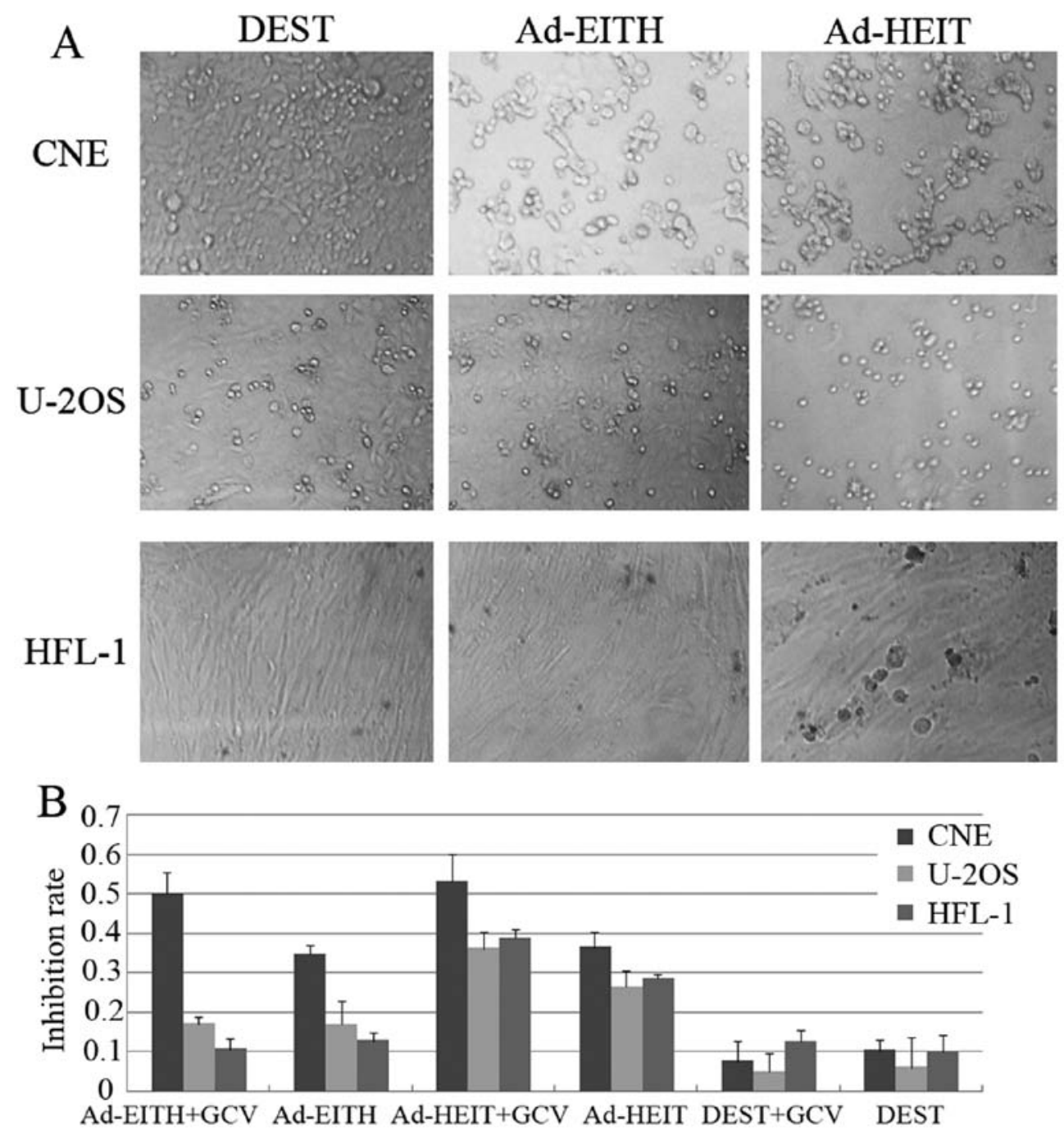

Figure 6. Cytotoxicity of recombinant adenoviruses in cell lines. Cytotoxicity of recombinant adenoviruses Ad-EITH and Ad-HEIT to tumor cells was evaluated by CCK-8 assay. (A) Morphology observation. (B) Results of CCK-8 assay showed that Ad-EITH had a better specificity to kill hTERTp (+) tumor cells than Ad-HEIT. Results also showed that GCV could enhance the antitumor effects of Ad-EITH and Ad-HEIT because of the suicide gene TK. Error bar: mean $\pm \mathrm{SD}$ of five independent experiments.

cation-essential genes or by using tumor-specific promoters, recombinant viruses could replicate in tumor cells specifically, cause rapid apoptosis of infected cells and result in massive killing of cells with no influence to normal cells. The foreign gene such as the suicide gene could be inserted into oncolytic virus to enhance the antitumor effects. HSV-TK/GCV suicide gene therapy has been used in clinical trial and has resulted in some clinical improvement (22). Moreover, many new therapeutic methods and tools have been emerging in large numbers to improve the effectiveness and safety of gene therapy in cancer treatment (23).

Herein, we utilized adenovirus as the therapeutic vector to construct a novel recombinant adenoviral expression vector pAd-EITH which could co-express E1A and HSV-1-TK gene by using hTERT promoter and IRES element, and we also cloned the hTERTp-TK-IRES-E1A downstream L-ITR with reverse direction and hTERTp was distant from the L-ITR in consideration of the promoter and enhancer activity of L-ITR for better replication specificity. We also constructed pAdHEIT in which hTERTp-TK-IRES-E1A downstream of L-ITR with the same direction to compare the difference of replication and antitumor characteristics between Ad-EITH and Ad-HEIT in tumor cells. Then, recombinant adenoviruses Ad-EITH and Ad-HEIT were produced by transfected linearized pAd-EITH and pAd-HEIT DNA and the replication activity and antitumor characteristics were evaluated. Results showed that Ad-EITH and Ad-HEIT replicated in hTERTp (+) human nasopharyngeal carcinoma cell line CNE cells effectively, but in hTERTp (-) human osteosarcoma cell line U-2OS cells and human lung fibroblasts HFL-1 cells, Ad-EITH was hardly able to replicate while Ad-HEIT still replicated in a small quantity, therefore we considered that $5^{\prime}$ L-ITR could disturb the regulation of the promoter and expression of gene downstream, which reduced the specificity of Ad-HEIT. To our surprise, the results in ACV sensitivity assay showed that ACV inhibited the replication of Ad-EITH and Ad-HEIT. ACV can induce the inhibition of viruses (especially HSV-1) replication by inhibiting DNA synthesis of the host cells. TK gene in Ad-EITH and Ad-HEIT was amplified from the genome of wHSV-1 sensitive to antivirus drug ACV in clinic and cloned into Ad-EITH and 
Ad-HEIT, so that these two recombinant adenoviruses could be sensitive to ACV such as wHSV-1.

In our study, we demonstrated that Ad-EITH could inhibit the grow th of CNE with no significant difference from Ad-HEIT, while the cytotoxicity of Ad-EITH to U-2OS and HFL-1 cells were subdued because of the improved replication specificity. The results also showed that GCV enhanced the antitumor effects of Ad-EITH and Ad-HEIT because the expression of the TK gene could transform GCV to a cytotoxic product and induced bystander effects among tumor cells in vitro. Hence, we thought that recombinant adenovirus Ad-EITH had better replication specificity compared to Ad-HEIT, and improved effectiveness and safety because of the HSV-1-TK gene, which not only enhanced the antitumor effect simultaneously but also caused Ad-EITH sensitivity to ACV, which meant that we could use ACV to eliminate residual therapeutic viruses and reduce side effects in future clinical application. TK gene and E1A gene were regulated by the same promoter hTERTp and co-expressed, to make sure that non-target cells would not be damaged by TK gene expression. Ad-EITH replicated conditionally in P53 (-) cells because of the deleted E1B-55 kd gene, whereas E1A was regulated by hTERTp to make sure Ad-EITH replicated in tumor cells expressing specifically the hTERTp.

Ad-EITH is a potential novel oncolytic adenovirus that kills tumor cells effectively and specifically with sensitivity to ACV improving the safety of Ad-EITH greatly. Further study in vivo and in clinic trials need to be carried out to obtain more evidence for future clinical application.

\section{References}

1. Swisher SG, Roth JA, Komaki R, Gu J, Lee JJ, Hicks M, Ro JY, Hong WK, Merritt JA, Ahrar K, Atkinson NE, Correa AM, Dolormente M, Dreiling L, El-Naggar AK, Fossella F, Francisco R, Glisson B, Grammer S, Herbst R, Huaringa A, Kemp B, Khuri FR, Kurie JM, Liao Z, McDonnell TJ, Morice R, Morello F, Munden R, Papadimitrakopoulou V, Pisters KM, Putnam JB Jr, Sarabia AJ, Shelton T, Stevens C, Shin DM, Smythe WR, Vaporciyan AA, Walsh GL and Yin M: Induction of p53-regulated genes and tumor regression in lung cancer patients after intratumoral delivery of adenoviral p53 (INGN 201) and radiation therapy. Clin Cancer Res 9: 93-101, 2003.

2. Gabrilovich DI: INGN 201 (Advexin): adenoviral p53 gene therapy for cancer. Expert Opin Biol Ther 6: 823-832, 2006.

3. Liu XY: Targeting gene-virotherapy of cancer and its prosperity. Cell Res 16: 879-886, 2006.

4. Pin RH, Reinblatt M and Fong Y: Utilizing alpha-fetoprotein expression to enhance oncolytic viral therapy in hepatocellular carcinoma. Ann Surg 240: 659-666, 2004.

5. Jakubczak JL, Ryan P, Gorziglia M, Clarke L, Hawkins LK, Hay C, Huang Y, Kaloss M, Marinov A, Phipps S, Pinkstaff A, Shirley P, Skripchenko Y, Stewart D, Forry-Schaudies S and Hallenbeck PL: An oncolytic adenovirus selective for retinoblastoma tumor suppressor protein pathway-defective tumors: dependence on E1A, the E2F-1 promoter, and viral replication for selectivity and efficacy. Cancer Res 63: 1490-1499, 2003.

6. Dilley J, Reddy S, Ko D, Nguyen N, Rojas G, Working P and Yu DC: Oncolytic adenovirus CG7870 in combination with radiation demonstrates synergistic enhancements of antitumor efficacy without loss of specificity. Cancer Gene Ther 12: 715-722, 2005.
7. Uchino J, Takayama K, Harada A, Kawakami Y, Inoue $H$ Curiel DT and Nakanishi Y: Infectivity enhanced, hTERT promoter-based conditionally replicative adenoviruses are useful for SCLC treatment. Cancer Gene Ther 12: 737-748, 2005.

8. Irving J, Wang Z, Powell S, O'Sullivan C, Mok M, Murphy B, Cardoza L, Lebkowski JS and Majumdar AS: Conditionally replicative adenovirus driven by the human telomerase promoter provides broad-spectrum antitumor activity without liver toxicity. Cancer Gene Ther 11: 174-185, 2004.

9. Zou W, Luo C, Zhang Z, Liu J, Gu J, Pei Z, Qian C and Liu X: A novel oncolytic adenovirus targeting to telomerase activity in tumor cells with potent. Oncogene 23: 457-464, 2004.

10. Tang XJ, Wang YP, Zhou QH, Che GW, Chen XH and Zhu DX: A study on selective killing effect of Hsv-tk/GCV driven by human telomerase catalytic subunit promoter on human lung cancer cell A549. Zhonghua Yi Xue Yi Chuan Xue Za Zhi 24: 148-152, 2007 (In Chinese).

11. Painter RG, Lanson NA Jr, Jin Z, Park F and Wang G: Conditional expression of a suicide gene by the telomere reverse transcriptase promoter for potential post-therapeutic deletion of tumorigenesis. Cancer Sci 96: 607-613, 2005.

12. Jiang YX, Lu Y, Liu TJ, Yang J, Chen Y and Fang YW: Using HSV-TK/GCV suicide gene therapy to inhibit lens epithelial cell proliferation for treatment of posterior capsular opacification. Mol Vis 17: 291-299, 2011.

13. Zhang Y, Wang CW, Wang ZG, Ma DX, Pan S, Zhu SG, Li F and Wang B: Construction of double suicide genes system controlled by MDR1 promoter with targeted expression in drug-resistant glioma cells. J Neurooncol 86: 3-11, 2008.

14. Huagn Y, Xu YM, Zhang JW, Ren XH and Suo AQ: Effects of estrogen on P-Tau, ChAT and nerve growth factor protein expressions in the brain tissue of rats with Alzheimer's disease. Nan Fang Yi Ke Da Xue Xue Bao 30: 2408-2410, 2010 (In Chinese).

15. Geoerger B, Grill J, Opolon P, Morizet J, Aubert G, Lecluse Y, van Beusechem VW, Gerritsen WR, Kirn DH and Vassal G: Potentiation of radiation therapy by the oncolytic adenovirus d11520 (ONYX-015) in human malignant glioma xenografts. Br J Cancer 89: 577-584, 2003.

16. Khuri FR, Nemunaitis J, Ganly I, Arseneau J, Tannock IF, Romel L, Gore M, Ironside J, MacDougall RH, Heise C, Randlev B, Gillenwater AM, Bruso P, Kaye SB, Hong WK and Kirn DH: A controlled trial of intratumoral ONYX-015, a selectively-replicating adenovirus, in combination with cisplatin and 5 -fluorouracil in patients with recurrent head and neck cancer. Nat Med 6: 879-885, 2000.

17. Xing L and Tikoo SK: E1A promoter of bovine adenovirus type 3. J Gen Virol 87: 3539-3544, 2006.

18. Yamamoto M, Davydova J, Takayama K, Alemany R and Curiel DT: Transcription initiation activity of adenovirus left-end sequence in adenovirus vectors with el deleted. J Virol 77: 1633-1637, 2003.

19. Li C, Hirsch M, Carter P, Asokan A, Zhou X, Wu Z and Samulski RJ: A small regulatory element from chromosome 19 enhances liver-specific gene expression. Gene Ther 16: 43-51, 2009.

20. Reed LJ and Muench H: A simple method of estimating fifty percent endpoints. Am J Hygiene 27: 493-497, 1938.

21. Bischoff JR, Kirn DH, Williams A, Heise C, Horn S, Muna M, Ng L, Nye JA, Sampson-Johannes A, Fattaey A and McCormick F: An adenovirus mutant that replicates selectively in p53-deficient human tumor cells. Science 274: 373-376, 1996.

22. Niculescu-Duvaz I and Springer CJ: Introduction to the background, principles, and state of the art in suicide gene therapy. Mol Biotechnol 30: 71-88, 2005.

23. Zhang X, Zhao L, Hang Z, Guo $\mathrm{H}$ and Zhang M: Evaluation of HSV-1 and adenovirus vector-mediated infection, replication and cytotoxicity in lymphoma cell lines. Oncol Rep 26: 637-644, 2011. 